\title{
Resenha
}

\section{Sobre perspectivismo e verdade em Nietzsche}

\section{LIMA, Márcio José Silveira. As Artes de Proteu: Perspectivismo e verdade em Nietzsche. Curitiba/São Paulo: CRV/Humanitas, 2018. 172 p.}

Daniel F. Carvalho*

Na obra As artes de Proteu: Perspectivismo e verdade em Nietzsche, Márcio José Silveira Lima desenvolve uma reflexão sistemática sobre o embate de Nietzsche com a questão da verdade, analisando desde os escritos de juventude até o período final de sua produção filosófica e tendo como fio condutor o tema do perspectivismo.

\footnotetext{
* CEFET-MG, Belo Horizonte, Minas Gerais, Brasil.

ORCID https://orcid.org/0000-0002-7392-0743

Correio eletrônico: daniphilos@gmail.com
} 
Carvalho, D. F.

Na "Introdução" da obra, que está dividida em três capítulos, o autor chama atenção para o caráter paradoxal do estatuto do tema do perspectivismo na obra nietzschiana: ao mesmo tempo em que ocupa uma posição central, na medida em que a filosofia nietzschiana é ela própria perspectivista, o perspectivismo nietzschiano parece periférico, se levamos em consideração o modo como ele é apresentado em sua obra e o tratamento que a ele é dispensado: na obra publicada ele aparece em apenas três ocasiões: em dois aforismos de $A$ gaia ciência e em um parágrafo de Genealogia da moral. Já na "Introdução" fica claro que Lima procura iluminar o perspectivismo nietzschiano a partir do seu diálogo com o criticismo kantiano, ambos entendidos como formas de filosofar pretensamente antidogmáticas. Pretensamente porque, como o autor procura mostrar, Nietzsche ao longo de sua obra passa a entender o próprio criticismo kantiano como dogmático, e é a partir do tensionamento da filosofia crítica kantiana e da denúncia dos limites que a constituem, como a impossibilidade do intelecto realizar sua própria autocrítica, que Nietzsche desenvolve sua filosofia perspectivista: o olhar do intelecto sobre si mesmo já é limitado pelo fenomenalismo da consciência, não há modo de ultrapassar o caráter interpretativo que constitui a própria existência, pois "aquilo o que ele pode saber sobre si é apenas uma perspectiva simplificada de um "mundo interior' riquíssimo" (p.25).

Na leitura de Lima, o perspectivismo nietzschiano aparece no período final de sua obra como um ponto de chegada das reflexões de Nietzsche em torno do problema do conhecimento e como solução tanto para as limitações do projeto crítico kantiano como para as abordagens sobre dogmatismo e verdade encampadas por Nietzsche no seu período inicial de produção, como em Sobre verdade e mentira no sentido estra-moral, texto no qual o filósofo procura superar a abordagem kantiana por meio da substituição de uma concepção lógica por uma retórica de linguagem. É apenas a partir do momento em que Nietzsche amplia o escopo de sua própria crítica para além 
da concepção da verdade como correspondência metafísica e passa a sustentar a tese de que somos nós quem impomos nossas interpretações à efetividade e à nossa compreensão do "mundo interior" que o perspectivismo pode "questionar a metafísica, assim como as noções que justificam e fundamentam a noção de conhecimento seguro" (p.27), associando o empreendimento metafísico, assim como a filosofia crítica, a um mesmo eixo comum valorativo: o da vontade de verdade. O objetivo do autor, pois, é "identificar na obra de Nietzsche uma caracterização do perspectivismo e defender um lugar central para ele em sua obra", de modo que seu "estudo compreende o perspectivismo como um combate ao dogmatismo, e uma tentativa de desmascarar as crenças escondidas pela vontade de verdade" (p.27).

Lima defende em seu livro cinco teses acerca do perspectivismo:

primeira, ele retoma problemas e questões da filosofia crítica de Kant; segunda, aparece nas obras tardias a fim de solucionar impasses e contradições dos escritos iniciais sobre a verdade; terceira, ao rejeitar a noção de verdade, afirma que todos os pontos de vista são interpretações; quarta, associando-se à vontade de potência [Wille zur Macht], apresenta uma concepção de hierarquia de interpretações que afasta o relativismo; quinta, a superação da vontade de verdade conduz o próprio filosofar nietzschiano como efetivação do perspectivismo. (p.27)

Após anunciar o objetivo e as teses centrais de sua obra, o autor desenvolve ainda na "Introdução" uma discussão com várias leituras mais recentes do perspectivismo nietzschiano, como as leituras de Antônio Marques, Maudemarie Clark, Alexander Nehamas, dentre outros, na qual é possível entrever alguns direcionamentos de sua argumentação em favor de sua própria perspectiva acerca do perspectivismo. 
Carvalho, D. F.

No primeiro capítulo, intitulado "O Problema do Conhecimento: metáfora versus verdade", Lima desenvolve uma leitura na qual procura mostrar que os primeiros embates de Nietzsche com a questão da verdade acabam por levá-lo a uma aporia. Tomando como base os escritos $O$ nascimento da tragédia, A filosofia na época trágica dos gregos e, sobretudo, o texto Sobre verdade e mentira no sentido extra moral, a tese defendida pelo autor ao longo do capítulo é a de que Nietzsche, nesse momento de sua produção intelectual, "se apropria e reelabora a crítica de Kant à metafísica realista dogmática a partir do combate à verdade" (p.48). Desde cedo desconfiado de que o ser humano possa ter acesso a um conhecimento do mundo em si mesmo, é no idealismo transcendental kantiano, na ideia de que o conhecimento não está fundado na experiência, mas se desenvolve a partir da própria constituição subjetiva humana, que Nietzsche encontra as armas para travar a sua luta.

Nietzsche herdaria de Kant elementos básicos de sua arquitetônica, rejeitaria, porém, a ideia de universalidade das intuições e dos conceitos, pensando as condições necessárias do conhecimento a partir de uma visão naturalista, como elementos incrustados na fisiologia humana ao longo do devir histórico-natural. É assim que Nietzsche substitui a dedução transcendental das categorias do entendimento operada por Kant por uma investigação histórico naturalista das condições que impulsionaram o surgimento e desenvolvimento do intelecto, ecoando com isso toda uma releitura do idealismo transcendental de Kant em viés naturalista que vinha sendo desenvolvida ao longo do século XIX, como as elaboradas por Helmholtz e Lange, por exemplo.

Ao mesmo tempo em que se apropria e reelabora o idealismo transcendental kantiano, conferindo um papel ativo à experiência e preconizando a impossibilidade de se dissociar razão teórica e prática, na medida em que o próprio desenvolvimento do intelecto ocorre em função de pressões externas, tanto de ordem natural 
quanto social, Nietzsche desenvolve, em Sobre verdade e mentira no sentido extra moral, uma análise radical da linguagem que, como mostra o autor, acaba incidindo sobre o próprio aparato crítico kantiano de que o filósofo se municia em sua crítica ao realismo dogmático da metafísica. São as necessidades, as experiências do homem enquanto ser natural que vive em sociedade que culminam com a fabricação dos conceitos, sendo necessário, portanto, realizar uma investigação genealógica que permita iluminar o caminho até a sua confecção.

É neste ponto que Nietzsche desenvolve sua concepção metafórica da linguagem, entendendo que a formação dos conceitos é precedida por todo um percurso de transposições metafóricas em diferentes níveis, que vão desde o estímulo nervoso, passando pela elaboração metafórica de uma imagem, sua transposição metafórica em um som, a formação das palavras até por fim se chegar à sua uniformização em um conceito. O que importa a Nietzsche é mostrar que na base do nosso conhecimento o que está em jogo são metáforas, que é pelo esquecimento das diferenças, é pelo procedimento de tomar o semelhante como idêntico, de igualação do não igual, que chegamos à formação dos conceitos: "Em vez da verdade, o conhecimento produz metáforas. Essa é, portanto, a modificação precípua que Nietzsche impõe ao idealismo kantiano" (p.58).

No afã de criticar o pathos da verdade, contudo, o entrelaçamento entre idealismo transcendental e crítica da linguagem acabaria gerando problemas, na medida em que o primeiro é inseparável de uma concepção lógica da linguagem, e esta se vê demolida pela concepção metafórica da linguagem elaborada por Nietzsche. O filósofo alemão, em sua crítica da verdade via crítica da linguagem, não teria como alvo, contudo, apenas o realismo dogmático, a possibilidade de um conhecimento da coisa em si, mas a própria possibilidade de correspondência entre o pensamento e as coisas que se expressa na lógica, tal como defendida pelo idealismo transcendental, de 
Carvalho, D. F.

modo que a crítica de Nietzsche via linguagem acaba incidindo sobre o próprio aparato kantiano de que ele se vale para criticar o dogmatismo metafísico. De acordo com Lima, Nietzsche percebe esse problema, mas não consegue encontrar uma solução satisfatória para ele, recuando por fim das consequências mais radicais de sua posição frente à verdade em função do perigoso ceticismo ao qual ela parece conduzir.

Diante da possibilidade de que a natureza seja inteiramente desprovida de regularidade, tudo não passando de uma criação extremamente subjetiva de sujeitos que chegam a um acordo em função de necessidades estritamente sociais, sem que haja qualquer relação de fato entre conceitos e objetos, Nietzsche retrocede, encontrando apoio para afastar a possibilidade do subjetivismo extremo na percepção da regularidade das leis da natureza e na inviolabilidade das representações de tempo e espaço, estas entendidas então como o aspecto transcendental da fisiologia humana e que asseguraria a percepção das leis naturais. Como o autor procura mostrar, Nietzsche também lança mão da ideia de causalidade e invoca os números como "orquestradores da regularidade com que a natureza se mostra à percepção", mas "não explica como é possível ao intelecto lançar mão desses dois conceitos" (p. 70). Por não possuir uma concepção própria que lhe permita combater a verdade sem cair no perigoso ceticismo a que sua visão metafórica da linguagem o conduz, sustenta o autor, Nietzsche acaba realizando "uma apropriação ambígua do idealismo transcendental, assumindo o que ele pretendia negar" (p.70). Esse impasse, como o autor procura mostrar, só será superado a partir do momento em que Nietzsche desenvolve uma concepção própria, o perspectivismo.

No capítulo II, intitulado "Perspectivismo versus Verdade", Lima desenvolve aquilo que julgamos constituir o núcleo do seu trabalho: a apresentação do perspectivismo como uma solução para os impasses aos quais Nietzsche é levado nos seus escritos de juventude 
no seu embate com o dogmatismo e a problemática da verdade. Para o autor, "o perspectivismo constitui um passo decisivo para a visão de Nietzsche sobre a verdade (p.79). Se nos escritos de juventude Nietzsche ficaria ainda preso a problemas insolúveis em função da sua tentativa de conciliar aspectos do idealismo transcendental kantiano com uma concepção radicalmente retórica de linguagem, a partir da década de 1880, especialmente nos fragmentos póstumos, Nietzsche endereça o problema da verdade a partir da ideia do perspectivismo como um tipo de fenomenalismo da consciência.

Nos fragmentos do período inicial da década de 1880 Nietzsche desenvolve a ideia de que o ser humano não possui nenhum órgão específico para a busca da verdade e que o conhecimento não pode se furtar à "perspectividade com que o homem pode se relacionar com $o$ mundo" (p.80). O conhecimento é apenas uma forma do ser humano agarrar o mundo, de fixá-lo com vistas à sua própria sobrevivência, de modo que mesmo no conhecimento científico não se pode obliterar o fato de que ele é ao mesmo tempo lógico e poético, de que ele cria e inventa o mundo com vistas às necessidades humanas.

Embora reconheça que alguns aforismos presentes nos primeiros quatro livros da obra A gaia ciência se utilizem da metáfora da perspectiva, é somente no quinto livro, incluso na segunda edição da obra e publicado no ano de 1886, que aparece o significado filosófico do perspectivismo, nas ideias de fenomenalismo da consciência e na possiblidade de infinitas interpretações. Nos aforismos 354 e 374, Nietzsche se contrapõe à verdade ao alegar que o que existe são interpretações, não fatos e, por meio de uma análise da consciência, conclui que o pensamento é sempre perspectivo.

Partindo de uma minuciosa leitura do aforismo 354, Lima mostra como, na perspectiva de Nietzsche, a consciência 1) não é algo originário, mas um desenvolvimento tardio na história humana, ligada à vida gregária e à necessidade de comunicação, e que 2) ela possui, abaixo de si, todo um universo múltiplo e beligerante de 
Carvalho, D. F.

afetos e impulsos que nunca chegam sequer a se tornar conscientes. Surgindo das necessidades do ser humano em virtude da vida gregária, a consciência não é nada além de uma rede de ligação entre as pessoas, não fazendo parte sequer da existência individual.

Por meio de uma abordagem na qual conecta reflexões sobre a linguagem, a consciência e a fisiologia, Nietzsche novamente se aproximaria do tipo de abordagem que utilizara em Sobre verdade e mentira no sentido extra-moral, com a diferença de que, no contexto de $A$ gaia ciência, ele abandona aquilo que antes estava pressuposto no período de juventude e que o encerrara num impasse: intuições e conceitos são vistos agora como perspectivas por meio das quais o pensamento se apodera das coisas, sendo os conceitos uma resultante tardia do desenvolvimento da linguagem. Mesmo o princípio de identidade, que está na base da lógica, seria interpretado no período intermediário dos escritos de Nietzsche como resultado das estratégias de sobrevivência que os seres humanos herdaram dos organismos inferiores na sua lida com uma realidade radicalmente processual, em fluxo, enfim, como forma de estabilizar o devir. Se há entendimento entre os seres humanos isso se deveria não à suposta universalidade de faculdades, conceitos e intuições, "mas porque as vivências são partilhadas e a linguagem as traduz" (p.88). O conhecimento, portanto, não seria outra coisa além de uma "simplificação dos estados internos e generalização da pluralidade efetiva do mundo", ou seja, "uma perspectiva superficial expressa em signos de linguagem" (p.89). Com a compreensão do perspectivismo enquanto um fenomenalismo da consciência, Nietzsche amplia sua crítica à verdade e mina as pretensões de certeza e de justificação características da modernidade, corporificadas nas filosofias de Descartes e Kant, respectivamente.

Com o aforismo 374, então, ao indagar "até onde vai o caráter perspectivista da existência, ou mesmo se ela tem outro caráter" ( $F W /$ $G C$ 374, KSA 3.626), Nietzsche abriria o mundo à possibilidade de 
que ele encerre infinitas interpretações e, com isso, "apresenta a interpretação como elemento definidor do perspectivismo" (p.95). Com a ideia de interpretação e de fenomenalismo da consciência, argumenta Lima, o perspectivismo nietzschiano passa a enxergar o conhecimento como uma ótica de perspectiva da vida que se alicerça em última instância na luta entre os impulsos que constituem o ser humano. Se Kant teve o mérito de dar um primeiro passo na luta contra o dogmatismo, e Nietzsche se serviu de seu idealismo nos escritos de juventude em seu combate à verdade, ele ainda estaria preso à oposição entre fenômeno e coisa em si, à distinção entre lógica da verdade e lógica da aparência, princípios constitutivos e regulativos. No perspectivismo nietzschiano, argumenta Lima, todos os princípios que na filosofia kantiana recebem o status de constitutivos serão reinterpretados pelo filósofo como princípios regulativos, como erros, interpretações, ficções úteis sob a ótica da vida. Após mostrar como Nietzsche radicaliza aspectos da Dialética transcendental kantiana, levando às últimas consequências a ideia de que o conhecimento humano só produz ficções, o autor encerra o capítulo com uma discussão acerca da vontade de potência enquanto um tipo de ficção que ultrapassa o âmbito da experiência e que será empregada por Nietzsche não apenas como interpretação, mas como critério de avaliação das interpretações.

No capítulo III, intitulado "Perspectivismo e Vontade de potência: para além da verdade e do relativismo", Lima enfrenta dois problemas que emergem do perspectivismo nietzschiano: em primeiro lugar, o problema da autorreferência e, em segundo lugar, o problema do relativismo. Ora, se Nietzsche argumenta que não podemos ir além de nossas perspectivas, elaborando apenas interpretações acerca do mundo, não seria o próprio perspectivismo apenas uma interpretação possível? Se tudo é interpretação, se não podemos ir além de nossa esquina, isso não significa que a própria afirmação de que tudo é interpretação seja ela mesma apenas uma interpretação? 
Carvalho, D. F.

Isso significa, ademais, que todas as interpretações se equivalem? Mesmo que a vontade de potência seja fornecida por Nietzsche como contraponto às interpretações dogmáticas, não seria ela apenas, também, uma interpretação? Que razões o filósofo mobiliza para defender a superioridade de sua interpretação sobre as demais? $\mathrm{Na}$ sua argumentação em favor da vontade de potência como critério para avaliar as interpretações Nietzsche não acabaria recaindo naquilo que ele mesmo procura combater, isto é, o dogmatismo movido pela vontade de verdade a todo custo?

Partindo de uma análise do $§ 22$ de Para além de bem e mal, no qual Nietzsche objeta à interpretação dos fenômenos naturais realizada pela física sua própria interpretação de mundo como vontade de potência, o autor procura enfrentar o problema da autorreferência, em primeiro lugar, por meio de uma discussão acerca do sentido da expressão "tanto melhor", que o filósofo utiliza neste parágrafo como resposta à possível objeção do físico de que a visão do mundo como vontade de potência também não seria nada mais que uma interpretação. Márcio Lima mostra que nessa passagem o problema da autorreferência se torna evidente, uma vez que a objeção do físico, seguida pela resposta de Nietzsche, "tanto melhor", incide não apenas sobre a interpretação do mundo como vontade de potência, mas também sobre a tese de que "não há fatos, só interpretação" (p.121). Neste sentido, no interior de uma teoria que tem como tese central a proposição de que "a falsidade de um juízo não é um argumento contra tal juízo, pois importa o quanto ele favorece a vida" (p.120), o autor argumenta que o problema da autorreferência é estranho à filosofia de Nietzsche, que ele só é um verdadeiro problema para a filosofia dogmática e sua teoria do conhecimento, mobilizada pela vontade de verdade e pela crença na lógica, já denunciada por Nietzsche. A "acusação" de autorreferência do perspectivismo, portanto, seria não um problema, mas um trunfo para a filosofia nietzschiana, já 
que acaba revelando seu caráter eminentemente antidogmático, ela seria "um testemunho do seu êxito" (p.122).

Não seria possível dizer a mesma coisa, contudo, da acusação de relativismo, que constituiria na visão do autor um obstáculo maior ao perspectivismo nietzschiano. Se Nietzsche denuncia a vontade de verdade, entendida como o móbil de toda filosofia dogmática, e abandona a verdade como critério de avaliação, de que modo ele pretende "substituir a teoria do conhecimento por uma teoria perspectivista dos afetos?" (p.124). Que critério ele pode utilizar para reivindicar a superioridade dos seus argumentos sobre o de seus oponentes? Tais questões só poderiam ser respondidas, segundo o autor, através da compreensão da associação existente entre perspectivismo e vontade de potência. Se a primeira questiona a verdade, a segunda passa a oferecer não apenas uma outra interpretação de mundo, mas um novo critério de avaliação que permite ao filósofo dispor as interpretações segundo uma hierarquia. Ao afirmar que há apenas interpretações, portanto, Nietzsche não recai no relativismo, uma vez que se municia de um critério que o permite ranquear as diferentes interpretações.

Nietzsche associa a vontade de potência à vida, entendendo-a como expansão, violência, imposição de formas, domínio. Ao ocupar o lugar de critério por meio do qual as diversas interpretações serão hierarquizadas, a vontade de potência permitiria a Nietzsche não cair na concepção segundo a qual todos os pontos de vista se equivalem. As óticas de perspectiva que afirmam a vida, que a intensificam, que favorecem seu aspecto expansivo, ocupariam uma posição superior na hierarquia de interpretações. Arte e metafísica, por exemplo, são duas óticas de perspectiva da vida, são dois direcionamentos distintos da vontade de potência, mas enquanto a primeira intensifica a vida, cria, a segunda, movida pela vontade de verdade, duplica o mundo e nega a própria perspectividade. 
Carvalho, D. F.

Mas se a autorreferência não constitui um verdadeiro problema para o perspectivismo nietzschiano e se a vontade de potência imuniza Nietzsche da acusação de relativismo, essa mesma teoria não acaba arrastando o filósofo de volta para o dogmatismo que ele tanto critica? Ela não assume o lugar de "olho de Deus?" Para Lima, a associação entre perspectivismo e dogmatismo afastam Nietzsche tanto do relativismo quanto do dogmatismo. Neste ponto, sua interpretação parece se assemelhar àquela oferecida por Cristoph Cox no seu livro Naturalismo e interpretação, que o autor cita em uma de suas notas de rodapé. Para este autor, o aparente relativismo do perspectivismo nietzschiano seria posto em xeque pelo seu "naturalismo", que fornece as doutrinas do vir a ser e da vontade de potência no lugar de uma interpretação teológica, enquanto o aparente dogmatismo dessas duas doutrinas seria mitigado pelo seu perspectivismo, que admite que mesmo essas doutrinas seriam interpretações, embora superiores em função de seu caráter naturalista (Cf. COX, 1999, p.03). A vontade de potência na obra de Nietzsche, pois, não assumiria o lugar de "verdade", ela deveria ser entendida como "erro", como uma interpretação que, ao contrário das interpretações mobilizadas pela vontade de verdade, as quais Nietzsche desmascara genealogicamente, concebe ainda um lugar para as interpretações contrárias enquanto óticas de perspectivas de um determinado tipo de vida. Perspectivismo e vontade de potência, portanto, se complementam: enquanto esta última fornece um critério por meio do qual avaliar as diversas interpretações, sendo superior aquela que mais promove a vida, o perpectivismo faz com que, diante da exigência dogmática de um critério fundacionalista e lógico, a vontade de potência não reivindique para si nada além do status de interpretação.

Como argumenta o autor na conclusão do livro, o embate de Nietzsche com a verdade tal como ele se apresenta ao longo de toda sua produção filosófica é animado não apenas pela pesquisa acerca das 
condições que tornaram a verdade um valor fundamental e pela crítica da verdade, mas também pela reflexão acerca das consequências advindas da descrença na verdade. É assim que Nietzsche se põe a refletir sobre o niilismo, sobre um horizonte no qual, com a "morte de Deus", todos os supremos valores se desvalorizam e novos candidatos à guia da civilização emergem. Este seria o caso, por exemplo, da ciência na modernidade, que embora possa aparecer como uma alternativa, como adversária da metafísica e da religião, na medida em que seu progresso acaba destronando certas imagens acerca do homem e da natureza produzidas por ambas, revela-se finalmente como o último rebento desse mesmo impulso, na medida em que é movida pela vontade de verdade. A própria ciência, podemos concluir a partir da reflexão do autor, se revelaria como dogmática, na medida em que não acolhe em seu interior o caráter perspectivo de toda e qualquer produção humana, em que não se auto compreende como uma perspectiva.

Escrito em um estilo que torna agradável a leitura de um tema tão árido e espinhoso, o livro As artes de Proteu: perspectivismo e verdade em Nietzsche representa uma contribuição bem-vinda à interpretação do pensamento nietzschiano no Brasil, destacandose pelo esforço do autor em oferecer uma visão ampla e coerente do perspectivismo nietzschiano por meio de uma narrativa que percorre todos os períodos de sua produção filosófica e que enfrenta as principais problemáticas relacionadas ao tema sem desconsiderar as dificuldades que emergem dos textos do filósofo alemão, como bem observou o professor Clademir Araldi, que assina o prefácio da obra. 
Carvalho, D. F.

\section{Review}

On perspectivism and truth in Nietzsche

\section{Referências}

COX, Cristoph. Naturalism and interpretation. Berkeley: University of California Press, 1999.

LIMA, Márcio José Silveira. As Artes de Proteu: Perspectivismo e verdade em Nietzsche. Curitiba, PR: CRV, 2018. - Coedição: São Paulo, SP: Humanitas, 2018. $172 \mathrm{p}$.

NIETZSHE. Friedrich. A gaia ciência. Trad. Paulo César de Souza. São Paulo: Cia. das Letras, 2001.

Recebida: 25/06/2020

Aceita: 15/07/2020

236 | Cad. Nietzsche, Guarulhos/Porto Seguro, v.41, n.2, p. 223-236, maio/agosto, 2020. 